\title{
Relationship between fatigue and heart rate variability in mothers up to three months postpartum
}

\begin{abstract}
This study examines the validity of an objective assessment method for fatigue up to 3 months postpartum in women. Heart rate variability was analyzed to evaluate the state of the autonomic nervous functions. Sixteen mothers who were in their third or fourth day postpartum and who consented to take the "Subjective Symptoms Assessment" and to use a memory heart rate monitor for heart rate variability measurement on three occasions: third to fourth day postpartum, first month, and third month were included in the study. No significant differences in subjective symptoms during the three periods were noted; however, statistically significant differences of heart rate between each period were observed $(=369.7, p<0.001)$. Although significant changes cannot be detected based on subjective symptoms, identifying the state of autonomic nervous activity by analyzing heart rate variability could objectively indicate the fatigue state after childbirth.
\end{abstract}

Keywords: postpartum convalescence, fatigue, subjective symptoms, heart rate variability, autonomic nervous system
Volume 6 Issue 3 - 2017

\author{
Kyoko Tokoro,' Yoshiaki Ito, ${ }^{2}$ Yoko Emori, ${ }^{3}$ \\ Takayasu Kawaguchi \\ 'Nursing Science, Graduate School of Comprehensive Human \\ Sciences, University of Tsukuba, Japan \\ ${ }^{2}$ Department of Nursing, Tokyo University of Information \\ Sciences, Japan \\ ${ }^{3}$ Faculty of Medicine, University of Tsukuba, Japan
}

\begin{abstract}
Correspondence: Kyoko Tokoro, Nursing Science, Graduate School of Comprehensive Human Sciences, University of Tsukuba, Ibaraki-city, Japan, Tel/Fax +8I-43-235-73I9, Email tksa@mbn.nifty.com
\end{abstract}

Received: November 24, 2017 | Published: December 28, 2017
Abbreviations: HF, high frequency; LF, low frequency; LF/ $\mathrm{HF}$, the ratio of $\mathrm{LF}$ and $\mathrm{HF}$

\section{Introduction}

After giving birth, women undergo mental and physical changes, and they have increased household $\square$ chores and childrearing responsibilities in addition to the typical work at home and/ or the occupation they had before delivery. ${ }^{1}$ Despite this reality, no laws regarding health assessments of postpartum women exist, and assessment methods are seemingly inadequate. "Fatigue" is the most commonly identified subjective symptom among postpartum mothers. ${ }^{2}$ To assess fatigue, the "Subjective Symptoms Assessment", ${ }^{3}$ which has a high correlation to subjective fatigue, has been used in general clinical settings; however, it is limited as a quantitative measurement in itself. Currently, several reports on quantitative evaluation methods to measure fatigue, including a non-invasive test method using salivary alpha-amylase as a biomarker, ${ }^{4,5}$ a salivary cortisol test method, ${ }^{6}$ an actigraphic measurement method, ${ }^{7-9}$ and an autonomic nervous function measurement method, ${ }^{10}$ exist. However, the methods measuring cortisol and amylase in the saliva lack consistency, especially that the time of the day or the amount of saliva can affect the results. Additionally, actigraphs and autonomic nervous function measurements, as methods to quantitatively assess fatigue and emotion after childbirth, require the devices wearing for $24 \mathrm{~h}$; hence, the burden on the subject is large.

Recently, there has been an increase in research on using autonomic nervous function changes as indices for measuring fatigue. Two types of autonomic nervous function measurement methods were established: the 24-h time domain analysis method and the frequency domain analysis method. In particular, the latter can take measurements in a relatively short time and be used in various ways, including measuring changes in heart rate variability ${ }^{11,12}$ and accelerated plethysmography. ${ }^{10}$ The purpose of this study is not only to better assess the sense of fatigue among women within 3 months of childbirth a time when they are going through physical and mental changes and are thus physically and mentally vulnerable, thereby requiring intervention using the Subjective Symptoms Assessment (Working Group for Occupational Fatigue), but also to examine the possibility of identifying a new index to objectively assess the health of postpartum women by analyzing the relationship between fatigue and the autonomic nervous function based on heart rate variability.

\section{Materials and methods}

Mothers who were in their third or fourth day in the hospital recovering from childbirth were included in this study. In Japan, women typically stay in the hospital for postnatal care for 4 to 7 days after a vaginal delivery and 8 to 10days after cesarean section. Both written and verbal explanation of the purpose of the study was provided, and the Subjective Symptoms Assessment questionnaire was only given to those who had consented. The completed consent form and the Subjective Symptoms Assessment survey were collected in the postpartum recovery room the following day.

\section{Research subjects}

Inclusion criteria included women who carried a single child to full-term and delivered at a maternity clinic and who agreed to participate in this study on the third or fourth day, at the first month, and at the third month postpartum. Exclusion criteria as follows: 
i. Those who cannot understand Japanese and have complications, including gestational induced hypertension, diabetes, or severe anemia.

ii. Those who had lost a significant amount of blood during childbirth and had delivery-related complications that persist a month after delivery, including severe lingering pain after delivery, anemia or high blood pressure.

iii. Those who had mental illness, including schizophrenia, or depression.

iv. Those with premature infants or infants admitted to the neonatal intensive care unit.

v. Those with a child with a severe disability, including congenital malformation.

vi. Those likely to face severe life challenges postpartum.

\section{Survey and heart rate variability measurement}

Subjects' characteristics, including age; pregnancy and childbirth history; height and weight; medical and surgical history; smoking and drinking habits; obstetric events during pregnancy; duration of delivery; delivery method; amount of bleeding; data on preterm labor, obstetric hypertension, abnormal bleeding during pregnancy, and so on; and other information such as low birth weight, were obtained from the medical and delivery records. In relation to current physical and mental condition, the subjects were asked in the form of openended questions about their postpartum fatigue, sleep condition, presence or absence of physical pain, uterine bleeding status (lochia), breast milk secretion, and whether or not they were facing any challenges; their responses were recorded. The survey questionnaire consists of 30 symptoms categorized into three factors: "feeling of fatigue and sleepiness" (group I), "difficulty paying attention and focusing" (group II), and "discomfort in certain locations" (group III). The survey period was from March to July 2015. Heart rate variability measurement was performed on an examination bed in a quiet room (bed height $45 \mathrm{~cm}$ ) at least $2 \mathrm{~h}$ since the subject had her last meal. Room temperature was maintained around $25^{\circ} \mathrm{C}$. Sensors were placed in three areas in the body (No. II. induction) and electrodes were attached.

The measurement was initiated after achieving a stable recumbent position for approximately $5 \mathrm{~min}$ until a stable measurement was obtained. Subjects were instructed to assume the following positions: resting position $1(5 \mathrm{~min})$, standing position $(1.5 \mathrm{~min})$, and resting position $2(5 \mathrm{~min})$; the heart rate was measured at each position. Subjects were requested not to take deep breaths during the measurement. If they were with their infant, we had one of the staff watch over the infant for the entire duration of the procedure. Following the measurement, the Subjective Symptoms Assessment (Working Group for Occupational Fatigue) questionnaire was completed by the subjects and the session was concluded. The sessions were performed at three time points: third to fourth day (group 1), first month (group 2), and third month (group 3) postpartum.

\section{Heart rate variability analysis}

Heart rate variability was analyzed using a memory heart rate monitor (LRR-03; GMS Co., Ltd.). The detection sensitivity was $0.3-10 \mathrm{mV}$, and the RR interval measurement range was $200-5096 \mathrm{~ms}$. The HRV Realtime Frequency Analysis program (MemCalc, GMS
Inc., Tokyo, Japan) was used. Spectrum data analyzed as a heartbeat fluctuation component were determined by calculating the lowfrequency (LF) value (LF component $0.04-0.15 \mathrm{~Hz}$ ), high-frequency (HF) value (HF component $0.15-0.4 \mathrm{~Hz}$ ), and $\mathrm{LH} / \mathrm{FH}$ ratio, and were used as an indicator of autonomic nervous activity. Moreover, the analysis was conducted by comparing and examining month-to-month differences, and differences in each position were evaluated (resting 1 vs standing vs resting 2). Particularly, in relation to the degree of fatigue, the HF component (the activity index of the parasympathetic nervous system) was set as a representative value. The significance level was set at $5 \%$, and data were analyzed using SPSS version 22 (IBM Corp., Armonk, NY, USA).

\section{Results and discussion \\ Background of the subjects}

In total, 16 mothers were included in this study, of whom 8 were primiparous and the remaining 8 were multiparous. The mean age $( \pm \mathrm{SD})$ was 30.2(6.6), body mass index 23.9(3.5), and newborn birth weight 3318 (493.5)g (Table 1). All deliveries were at full-term. Childbirth methods were as follows: vaginal delivery (10), instrumentassisted delivery (vacuum or forceps; 4), and cesarean section (2). No smokers or habitual drinkers were noted (Table 1).

Table I Background of the subjects

\begin{tabular}{|c|c|}
\hline & Mean \\
\hline Age & $30.2(6.6)$ \\
\hline First-time mothers & 6 \\
\hline Experienced & 6 \\
\hline BMI & $23.9(3.5)$ \\
\hline Newborn weight (g) & $3318(493.5)$ \\
\hline Age & $\mathrm{n}$ \\
\hline 20-24 (years) & 2 \\
\hline $25-29$ & 6 \\
\hline $30-34$ & 4 \\
\hline $35-39$ & 2 \\
\hline$\geq 40$ & 2 \\
\hline BMI (kg/m2) & $\mathrm{n}$ \\
\hline$<18$ & 0 \\
\hline $18-24$ & 11 \\
\hline$\geq 25$ & 5 \\
\hline Gestational age (weeks) & $n$ \\
\hline$<36$ & 0 \\
\hline $37-41$ & 16 \\
\hline$>41$ & 0 \\
\hline Newborn weight (g) & $\mathrm{n}$ \\
\hline $2000-2499$ & 1 \\
\hline 2500-3999 & 14 \\
\hline$\geq 4000$ & 1 \\
\hline Delivery method & $n$ \\
\hline Vaginal & 10 \\
\hline Suction/forceps & 4 \\
\hline Cesarean section & 2 \\
\hline
\end{tabular}




\section{Month-to-month subjective symptoms assessment scores}

Average scores (SD) in the Subjective Symptoms Assessment were as follows:

i. Group I: 4.1(2.3) at zero months, 4.2(2.4) at the first month, and $3.0(2.5)$ at the third month postpartum;

ii. Group II: 1.4(2.3) at zero months, 2.5(3.1) at the first month, and $1.6(2.4)$ at the third month postpartum; and

iii. Group III: $1.8(1.3)$ at zero months, $1.4(1.5)$ at the first month, and 1.8(1.6) at the third month postpartum. No correlation was detected between these three periods (Table 2).

Table 2 Month-to-month Subjective Symptoms Assessment scores

\begin{tabular}{lllll}
\hline & & $\begin{array}{l}\text { Zero } \\
\text { months }\end{array}$ & First month & $\begin{array}{l}\text { Third } \\
\text { month }\end{array}$
\end{tabular} p-Value

$\begin{array}{llllll}\text { Symptoms } & & & & & \\ \text { Group I } & 16 & 4.1(2.3) & 4.2(2.4) & 3.0(2.5) & 0.28 \\ \text { Group II } & 16 & 1.4(2.3) & 2.5(3.1) & 1.6(2.4) & 0.438 \\ \text { Group III } & 16 & 1.8(1.3) & 1.4(1.5) & 1.8(1.6) & 0.663 \\ \text { Total } & 16 & 7.2(4.5) & 8.1(5.4) & 6.5(4.9) & 0.647\end{array}$

One way analysis of variance

Table 3 Change in heart rate due to body position (resting I)

\begin{tabular}{llllr}
\hline & Zero months & First month & Third month & \\
\cline { 2 - 4 } & $\begin{array}{l}\text { Median (Interquartile } \\
\text { Range) }\end{array}$ & Median (Interquartile Range) & Median (Interquartile Range) & p-value \\
\hline HR (bpm) & $71(65-78)$ & $67(62-71)$ & $66(62-73)$ & 369.7 \\
HF (ms2) & $239(106.0-481.0)$ & $363(216-672)$ & $332.5(184.3-538.8)$ & 247.1 \\
LF/HF & $1.5(.85-3.0)$ & $1.9(1.1-3.2)$ & $1.5(.67-3.25)$ & $<0.001$ \\
Kruskal-Wallis test & & & $<0.001$
\end{tabular}

Table 4 Correlation between HF values before and after body position change and the subjective symptoms score

\begin{tabular}{|c|c|c|c|c|c|c|c|c|}
\hline & HF median & HF resting 2-1 & $\begin{array}{l}\text { HF resting 1- } \\
\text { standing }\end{array}$ & $\begin{array}{l}\text { HF resting 2- } \\
\text { standing }\end{array}$ & Group I & Group II & Group III & Total 48 \\
\hline HF median & - & -0.038 & $0.822 * *$ & $0.544 * *$ & 0.022 & 0.086 & 0.237 & 0.121 \\
\hline HF resting 1-standing & & & - & $0.708^{* *}$ & -0.086 & 0.037 & 0.192 & 0.04 \\
\hline HF resting 2-standing & & & & - & 0.004 & 0.046 & $0.321^{*}$ & 0.12 \\
\hline Group II & & & & & & - & 0.098 & $0.789 * *$ \\
\hline Group III & & & & & & & - & $0.463^{* *}$ \\
\hline Total & & & & & & & & - \\
\hline \multicolumn{9}{|c|}{ Spearman's correlation coefficient } \\
\hline${ }^{* *} p<0.01,{ }^{*} p<0.05$ & & & & & & & & \\
\hline
\end{tabular}

Citation: Tokoro K, Ito Y, Emori Y, et al. Relationship between fatigue and heart rate variability in mothers up to three months postpartum. MOJ Womens Health. 20I7;6(3):39I-395. DOI: I0.15406/mojwh.20I7.06.00I56 
Table 5 Correlation between HF values before and after body position change, LF/HF, and subjective symptoms (in the case where the total of the subjective symptoms of the three groups as $>7$ )

\begin{tabular}{|c|c|c|c|c|c|c|c|c|c|c|c|c|}
\hline & $\begin{array}{l}\text { HF } \\
\text { median }\end{array}$ & $\begin{array}{l}\text { HF } \\
\text { resting } \\
2-1\end{array}$ & $\begin{array}{l}\text { HF } \\
\text { resting } \\
1- \\
\text { standing }\end{array}$ & $\begin{array}{l}\text { HF } \\
\text { resting } \\
2- \\
\text { standing }\end{array}$ & $\begin{array}{l}\text { LFHF } \\
\text { median }\end{array}$ & $\begin{array}{l}\text { LF/HF } \\
\text { resting } \\
1- \\
\text { standing }\end{array}$ & $\begin{array}{l}\text { LF/HF } \\
\text { resting } \\
2- \\
\text { standing }\end{array}$ & $\begin{array}{l}\text { LF/HF } \\
\text { resting } \\
2-1\end{array}$ & Group I & Group II & Group III & Total 22 \\
\hline HF median & - & 0.354 & $0.820 * *$ & $0.500 *$ & $-0.516^{*}$ & 0.107 & -0.027 & 0.113 & -0.073 & -0.144 & 0.131 & -0.048 \\
\hline $\begin{array}{l}\text { HF resting } \\
2-1\end{array}$ & & - & 0.298 & $0.843^{* *}$ & -0.26 & 0.315 & 0.258 & 0.011 & 0.014 & $-0.471^{*}$ & 0.499* & -0.111 \\
\hline $\begin{array}{l}\mathrm{HF} \\
\text { resting 1- } \\
\text { standing }\end{array}$ & & & - & $0.620 * *$ & $-0.517^{*}$ & 0.253 & 0.149 & 0.152 & -0.307 & -0.202 & 0.135 & -0.224 \\
\hline $\begin{array}{l}\mathrm{HF} \\
\text { resting 2- } \\
\text { standing }\end{array}$ & & & & - & -0.38 & 0.357 & 0.259 & 0.123 & -0.118 & -0.331 & 0.333 & -0.115 \\
\hline $\begin{array}{l}\text { LFHF } \\
\text { median }\end{array}$ & & & & & - & -0.247 & 0.037 & $-0.592 * *$ & 0.178 & 0.105 & 0.025 & 0.188 \\
\hline $\begin{array}{l}\mathrm{LF} / \mathrm{HF} \\
\text { resting 1- } \\
\text { standing }\end{array}$ & & & & & & - & $0.896^{* *}$ & 0.286 & -0.348 & -0.101 & 0.169 & -0.139 \\
\hline $\begin{array}{l}\mathrm{LF} / \mathrm{HF} \\
\text { resting 2- } \\
\text { standing }\end{array}$ & & & & & & & - & -0.064 & $-0.425^{*}$ & -0.113 & 0.191 & -0.173 \\
\hline $\begin{array}{l}\mathrm{LF} / \mathrm{HF} \\
\text { resting } \\
2-1\end{array}$ & & & & & & & & - & -0.057 & 0.059 & -0.388 & -0.128 \\
\hline Group I & & & & & & & & & - & $0.447 *$ & 0.006 & $0.840^{* *}$ \\
\hline Group II & & & & & & & & & & - & $-0.639 * *$ & $0.775^{* *}$ \\
\hline Group III & & & & & & & & & & & - & -0.181 \\
\hline
\end{tabular}

Spearman's correlation coefficient

$* * p<0.05, * p<0.01$

\section{Discussion}

Studies of postpartum changes in heart rate variability are sporadic. Month-to-month Subjective Symptoms Assessment scores do not change as time increases. It may suspect that the fatigue of postpartum women does not differ during the first 3 months, but it is unclear so the number of cases are not enough. Mothers' heart rates are likely to be high early after childbirth and decrease over time. This may be due to physiological effects of childbirth, which in turn lead to a reduction in circulating blood volume. In this study, the HF value at rest was highest at the first month. As the uterus contracts and recovers after birth, breathing deepens as the thorax widens, thereby physiologically affecting the HF value. Sympathetic and parasympathetic nervous systems have contrasting functions. In our study, both HF and LF/
HF were high during the first month. Particularly in their first month of motherhood, mothers experience less sleep and frequent mid-sleep interruptions. ${ }^{13}$ The first month is also a time when most mothers lose their social support systems; women in Japan return to their own home after staying with their parents for the first month postpartum. Furthermore, the increase in LF/HF ratio may be associated with short periods of sleep, childrearing responsibilities, and life in general. Particularly, just before individuals become sleepy, the HF value increases, and to compete with this rise in $\mathrm{HF}$ value, $\mathrm{LF} / \mathrm{HF}$ also increases. However, as our study did not quantitatively investigate the amount of sleep, we were unable to analyze its effect thoroughly; nevertheless, the lack of sleep in the first month after childbirth may be a factor in the increase of the HF value and LF/HF ratio. 
Moreover, we found that during position changes (resting 2 to 1 and resting 2 to standing), the HF value had a weak, negative correlation with group II and a weak, positive correlation with group III. When the sum of the subjective symptoms score is higher than the average ( $>$ 7items), the difference in the HF value with position changes and subjective symptoms exhibits a moderately negative correlation with the scores in group II $(\mathrm{r}=0.471, \mathrm{p}<0.05)$ and a moderately positive correlation with the scores in group III $(\mathrm{r}=0.499$, $\mathrm{p}<0.05)$. No prior studies considered the HF value before and after body position changes. The difference between the HF values before and after standing was small, which suggested that, in women after childbirth, the parasympathetic tone between position change is decreased when they have chronic fatigue, and are feeling frustrated. Mothers in group III indicated local discomfort, including headaches, shoulder stiffness, and back pain; however, the increased HF value could not be clearly established. Nevertheless, when individuals are busy, they are less likely to feel fatigued, and physical symptoms emerge once they finally take a break. This is probably because physical symptoms are likely to occur when the parasympathetic function is activated, which was manifested as subjective symptoms in the subjects of this study. Hence, in group II, where more symptoms were expressed, fewer changes in HF values were noted, thereby indicating fewer changes in the parasympathetic nervous system with position changes. Furthermore, with LF/HF ratio (standing-resting 1), a negative correlation with group II was noted; similarly, with LF/ HF ratio (standing-resting 2), a negative correlation with group I was noted. Therefore, with groups I and II, in which more symptoms were expressed, fewer changes in LF/HF ratio due to body position changes were observed. This suggests that, when the subjective symptoms are high, fatigue and sympathetic tone are reduced with position changes.

\section{Limitations}

This study only included 16 cases, which is insufficient to make a general conclusion. In addition, patient ages were not matched.

\section{Conclusion}

Our findings suggest that even in the absence of noticeable changes in the subjective symptoms, postpartum fatigue status can be objectively identified by evaluating the autonomic nervous activity via heart rate variability analysis.

\section{Acknowledgements}

This study was funded in part by a Grant-in-Aid for Scientific Research A from the Japanese Ministry of Education, Culture, Sports, Science and Technology.

\section{Conflicts of interest}

The authors have no conflicts of interest directly relevant to the content of this article.

\section{References}

1. Ministry of Internal Affairs and Communications, Statistics Bureau. Employment Status Survey Results (Ministry of Internal Affairs and Communications, Statistics Bureau), Japan; 2012.

2. Cheng CY, Li Q. Integrative review of research on general health status and prevalence of common physical health conditions of women after childbirth. Womens Health Issues. 2008;18(4):267-280.

3. Yoshitake H. Occupational fatigue: an approach from the subjective symptoms. Japan: The institute for science of labour; 1973. p. 21-33.

4. Bosch J, Brand H, Ligtenberg A, et al. The response of salivary protein levels and S-IgA to an academic examination are associated with daily stress. J Psychophysiol. 1998;12(4):384-391.

5. Skosnik PD, Chatterton RT Jr, Swisher T, et al. Modulation of attentional inhibition by norepinephrine and cortisol after psychological stress. Int J Psychophysiol. 2000;36(1):59-68.

6. Roberts AD, Wessely $\mathrm{S}$, Chalder $\mathrm{T}$, et al. Salivary cortisol response to awakening in chronic fatigue syndrome. Br JPsychiatry. 2004;184(2):136141.

7. Sadeh A, Lavie P, Scher A, et al. Actigraphic home-monitoring sleepdisturbed and control infants and young children: a new method for pediatric assessment of sleep-wake patterns. Pediatrics. 1991;87(4):494 499.

8. Kang MJ, Matsumoto K, Shinkoda $\mathrm{H}$, et al. Longitudinal study for sleep-wake behaviours of mothers from pre-partum to post-partum using actigraph and sleep logs. Psychiatry Clin Neurosci. 2002;56(3"):251-252.

9. So K, Buckley P, Adamson TM, et al. Actigraphy correctly predicts sleep behavior in infants who are younger than six months, when compared with polysomnography. Pediatr Res. 2005;58(4):761-765.

10. Minakuchi E, Ohnishi E, Ohnishi J, et al. Evaluation of mental stress by physiological indices derived from finger plethysmography. J Physiol Anthropol. 2013;32(1):17-17.

11. Laskar MS, Harada N. Assessment of autonomic nervous activity in hand-arm vibration syndrome patients using time- and frequencydomain analyses of heart rate variation. Int Arch Occup Environ Health. 1999;72(7):462-468.

12. Karita K, Nakao M, Nishikitani M, et al. Autonomic nervous activity changes in relation to the reporting of subjective symptoms among male workers in an information service company. Int Arch Occup Environ Health. 2006;79(5):441-444.

13. Barimani M, Vikström A, Rosander M, et al. Facilitating and inhibiting factors in transition to parenthood - ways in which health professionals can support parents. Scand J Caring Sci. 2017;31(3):537-546. 